\title{
Awareness of Fathers Regarding Newborn Danger Signs: Evidence from a Tertiary Level Hospital of Kathmandu, Nepal
}

\author{
Rajani Dangol, Ranjana Koirala \\ Nursing Sciences, Maharajgunj Nursing Campus, Tribhuvan University, Kathmandu, Nepal \\ Email: ranjanakoirala2070@gmail.com
}

How to cite this paper: Dangol, R. and Koirala, R. (2020) Awareness of Fathers Regarding Newborn Danger Signs: Evidence from a Tertiary Level Hospital of Kathmandu, Nepal. Open Journal of Nursing, 10, 194-207.

https://doi.org/10.4236/ojn.2020.102013

Received: December 20, 2019

Accepted: February 25, 2020

Published: February 28, 2020

Copyright $\odot 2020$ by author(s) and Scientific Research Publishing Inc. This work is licensed under the Creative Commons Attribution International License (CC BY 4.0).

http://creativecommons.org/licenses/by/4.0/

(c) (i) Open Access

\begin{abstract}
The neonatal period is a critical period of childhood carrying the highest risk of mortality per day than any other period during the childhood. In Nepal, a country where a neonatal mortality rate is high, raising awareness among fathers regarding newborn danger signs is crucial. This research aims to measure the awareness of fathers regarding newborn danger signs. A hospital based cross sectional descriptive study was done in maternity ward and birthing center of Tribhuvan University Teaching Hospital (TUTH) hospital. Non-probability purposive sampling technique was used to select fathers of neonate. The study was conducted on 103 fathers having newborn baby up to 7 days admitted in Maternity Ward and Birthing Center. Respondents were selected without any discrimination of education, ethnicity, economical status, marital status, religion, etc. The findings of the study showed that out of 103 respondents, most of the respondents had moderate level of awareness (63.1\%), 28.2\% had low level and minority of the respondents had high level of awareness $(8.7 \%)$. The researcher concluded that most of the respondents had a moderate level of awareness and minority of the respondents had a high level of awareness on newborn danger signs. The findings show greater need of health education to increase awareness about newborn danger signs among fathers.
\end{abstract}

\section{Keywords}

Newborn Danger Signs, Fathers' Awareness, Tertiary Level Hospital, Nepal

\section{Introduction}

Neonatal morbidity and mortality are a global issue despite the variance in the prevalence in developed and developing nations [1]. Globally, 2.5 million child- 
ren died in the first month of life in 2018 alone-approximately 7000 neonatal deaths every day-most of which occurred in the first week, with about 1 million dying on the first day and close to 1 million dying within the next six days [2]. Children face the highest risk of dying in their first month of life at an average global rate of 18 deaths per 1000 live births in 2017. In 2018, 40\% of all under-5 deaths occur within the first month of life and half of these within the first few days of life [3]. 17\% of neonatal deaths have occurred within the first hour of life. Overall, more than half of neonatal deaths have occurred within the first day of life $57 \%$ [4]. As expected, around $79 \%$ of all deaths have occurred within the early neonatal period of 0 - 6 days. Late neonatal deaths (7 - 27 days) account for the remaining 21\% [5] [6] [7]. Many of these deaths are related to late recognition of neonatal illness, delays in decision to seek care at household level and subsequent late intervention at healthcare facilities [8] [9] [10]. At family level, poor feeding and care practices after birth, lack of awareness on recognition of danger signs of illnesses (which are often subtle) further decrease their chances of survival and/or increase their chance of growing in a undernourished growth trajectory in and beyond this period [11] [12].

Neonates (i.e. the first 28 days of life) often present with non-specific symptoms and signs that indicate severe illness. These signs might be present at or after delivery or in a newborn presenting to hospital or develop during hospital stay [13] [14] [15] [16]. The most neonatal cases reported and treated were severe bacterial infections, local bacterial infections, hypothermia and jaundice [17]. The WHO recognized danger signs based on WHO definition signs include: not feeding well, convulsions, drowsy or unconscious, movement only when stimulated or no movement at all I fast breathing (60 breaths per min), grunting, severe chest in drawing, raised temperature, $\geq 37.5^{\circ} \mathrm{C}$, hypothermia, $\leq 35.5^{\circ} \mathrm{C}$, only moves when stimulated or not even when stimulated (lethargy or weakness), yellow sole (signs of jaundice), umbilical redness or draining pus, eye infection and skin boils [18]. Tremendous progress has been made in recent decades: between 1990 and 2016, neonatal mortality fell from 58.7 per 1000 live births in 2000 to 28.2 per 1000 in 2016 . The number of newborn deaths declined from 2.2 million in 2000 to 1 million in 2016 [3]. But nearly 2800 newborns still die each day in South Asia, although under-five deaths have reduced, newborn deaths as a proportion of under-five deaths have increased from 46 per cent in 1990 to a staggering 59 per cent in 2016 [2]. In 2016, the highest neonatal mortality rate was in Pakistan (46 per 1000 live births), followed by Afghanistan (40 per 1000 live births) [3].

The incidence of Neonatal Conjunctivitis has been reported from various regions of the world as $1 \%-24 \%$ [19]. A study from Pakistan concluded that there was a high frequency of neonatal conjunctivitis (17\%), with Staphylococcus aureus as the most common causative agent and also that poor hygienic conditions and practices could be an important risk factor in Pakistan [20]. In Belgium found that $11 \%$ of the infants had neonatal conjunctivitis before leaving the ma- 
ternity ward and another $12.66 \%$ infants were reported to have developed sticky eyes/red eyes before leaving the maternity hospital and before 1 month of age [21]. Narchi and Kulaylat [22] mentioned that in Saudi Arab, Feeding problems at the first feed developed in less than $1 \%-4.7 \%$ and $1.6 \%$ of cases with and without meconium stained amniotic fluid. It concluded that feeding problems were more common in infants with meconium stained amniotic fluid, regardless of the type of meconium stained amniotic fluid (thin or thick). A study on global burden of hypothermia found that prevalence of hypothermia is high ranging from $32 \%$ to $85 \%$ and $11 \%$ to $92 \%$ among newborn born in hospital and at home respectively [23].

Various interventions utilize male involvement to improve maternal and child health outcomes, however male involvement in newborn care is a relatively unexplored strategy [24] [25]. In Nepal, the percentage of neonatal cases has been reported and treated for the common newborn problems as possible severe bacterial infections $16.10 \%$, local bacterial infections $47.71 \%$, hypothermia $1.76 \%$ and jaundice $6.8 \%$. Of the total cases registered at national level, Total 5.81\% cases were referred; $0.69 \%$ and $7.79 \%$ were reported as death at Health Facility and community respectively [26]. The NDHS [27] shows that after nearly a decade of stagnation the neonatal mortality rate (NMR) has moved from 33 per 1000 live births to 21 per 1000-a decline of more than one-third from 2011. $17 \%$ of neonatal deaths have occurred within the first hour of life. Overall, more than half of neonatal deaths have occurred within the first day of life (57\%). As expected, around $79 \%$ of all deaths have occurred within the early neonatal period of 0 - 6 days. Late neonatal deaths ( 7 - 27 days) account for the remaining $21 \%$. Hence, the aim of initial management of a neonate presenting with these signs is stabilization and preventing deterioration [28].

Most newborn deaths are caused by three preventable and treatable issues: complications related to prematurity; birth complications including lack of oxygen (asphyxia); and newborn infections such as sepsis and pneumonia [3]. Many lives could be saved each year by investing in quality care around the time of birth, coupled with special care for sick and small newborns [2] [29] [30]. To the knowledge of the researcher, very few study till the date has focused on the status of awareness of fathers regarding newborn danger signs. So, the study was an attempt to identify the level of awareness of fathers regarding newborn danger signs. In specific, this study attempts 1) to identify the level of awareness among fathers regarding newborn danger signs and 2) to find out the association between the level of awareness and selected socio-demographic variables.

The paper is organized as follows. In the next section, we provide a short review on importance of fathers' awareness on newborn and newborn danger sings. Section 3 presents detail materials and methods used to conduct this study. Results and Discussions are presented in Section 4. The final section concludes this study with major output, its implication, limitations and area for future (and further) research. 


\section{Literature Review}

\section{Importance of Fathers Awareness on Newborn Signs}

In the 5 -year period preceding the survey, neonatal mortality was 21 deaths per 1000 live births. Slightly more than one-half $54 \%$ of all deaths in the first 5 years of life occur in the first month of life, an increase from $42 \%$ in 1996. As childhood mortality rates have declined, the burden of neonatal deaths has increased. The Nepal Health Sector Strategy 2016-2021 targets are to reduce neonatal mortality to 17.5 deaths per 1000 live births by the year 2021 [26]. The Sustainable Development Goal (SDG) targets related to neonatal mortality in Nepal are 12 deaths per 1000 live births by 2030. Neonatal mortality declined by $58 \%$ from 1996 to 2016 [26]. The two most common causes of neonatal death were respiratory and cardiovascular disorders of the perinatal period 31\% and complications of pregnancy, labor, and delivery $30 \%$. These are followed by neonatal deaths from infections specific to the perinatal period $16 \%$ and congenital malformations and deformations $7 \%$. Hypothermia accounts for $4 \%$, and disorders related to length of gestation and fetal growth account for $2 \%$ of neonatal deaths. Sudden neonatal deaths account for $6 \%$ of total deaths [26].

Even though mothers are the key person for providing newborn care, fathers also provide a significant contribution to their families and newborn [31]. Psychological research across the families from all ethnic background suggests that fathers' affection and increased family involvement help to promote children's social and emotional development [32]. Father protects mother-baby bond as well as also need to establish and nurture their own bonds with their children and can continue to strengthen their bond with baby in those first few weeks by establishing routines of care with feeding, bathing, changing diapers, putting to sleep, speak to the baby often to help with language development, provide physical contact like rocking, playing and infant massages [33].

Nepal has predominantly patriarchal society. All aspects of growth and development caring for the child are primarily provided by the mothers. The father is typically the breadwinner, moral teacher and a sex-role model. With increasing trend of women entering the work force and tendency of nuclear family, newborns are getting less attention and role of husband has become important in newborn care. Studies have shown that fathers are competent as mother in giving care if they have adequate knowledge. Each father of the newborn should be equipped with adequate knowledge about proper care of newborn baby [34] [35].

The government of Nepal has made the provision in Civil Service Act and Civil Service Regulation to provide paternal leave for 15 days after the delivery of baby. So that the fathers can be involved in newborn care along with the care of postpartum mother.

\section{Materials and Methods}

\subsection{Result Setting and Study Population}

A cross sectional descriptive study design was used to study to collect informa- 
tion on awareness of fathers regarding newborn danger sings. The study was carried out in maternity unit of Tribhuvan University Teaching Hospital (TUTH) Maharajgunj, Kathmandu. TUTH is a non-profitable hospital providing new-level health services situated in Kathmandu [36]. Selected wards of this hospital for the setting of this study were maternity ward and birthing center. Approximately 10 - 15 deliveries conducted per day in TUTH. At present, there are 700 beds in TUTH, among which maternity department have maternity ward which has 33 beds and birthing centre has 22 beds.

\subsection{Determinants of Sample Size}

The non-probability purposive sampling technique was used to determine the sample size. The fathers having child below the age of 7 days attending TUTH and who were willing to participate the study were include in the study. The fathers having newborn baby up to 7 days admitted in Maternity Ward and Birthing Center during data collection period (i.e. 2 weeks) were taken as the sample. The given formula was used to determine the sample size.

$$
n=\frac{z^{2} p q}{l^{2}}
$$

where, $n=$ sample size required for study, $z=$ standard tabulated value for $5 \%$ level of significance (i.e. $z=1.96$ ), $p=$ prevalence of lack of an event, $q=100-p$ and $I=$ Allowable error that can be tolerated.

In this study, the total sample size of the study was calculated considering $50 \%$ prevalence at $95 \%$ confidence level with $10 \%$ allowable error. The total number of required sample size is therefore 96 . This study also considered $5 \%$ of non-response error (i.e. $\approx 5)$. Hence, a total 102 is the required respondents. This study has set the inclusion criteria as: fathers having child below the age of 7days attending TUTH and who were willing to participate the study were included in the study.

\subsection{Data Collection and Analysis}

The instrument was based on the set objectives and literature review. The instrument was validated by consulting with advisor, subject expert, research committee member and peer for adequacy and accuracy of instrument. Instrument was translated into native language (i.e. Nepali language) and opinion of the language expert was obtained for comprehensibility and simplicity of language. To ensure the reliability of the test instrument pre-testing was performed in 10\% of the sample size in TUTH. Questionnaire was modified and finalized as the result of the pre testing. A structured self-administrative questionnaire was use. The data was collected by using the interview technique. Duration of interview was 15 - 20 minutes. Data was collected from the fathers of the neonate and as per their convenience. The purpose of the study was explained and informed consent was taken prior to data collection from the fathers of neonate. Anonymity and confidentiality of the information was maintained by encoding each res- 
pondent with numbers rather than their names and collected information was used only for the purpose of study. Respondents were selected without any discrimination of education, ethnicity, economical status, religion, etc. Data collection was done for two weeks on the month of October, 2018.

The collected data was reviewed daily for completion and accuracy. Data was coded, tabulated, organized and entered in Statistical Package for Social Science (SPSS) version 16.0 for analysis. The correct answers were coded 1 and incorrect were coded 0 . Descriptive statistics were used to describe the dependent and independent variables and interferential statistics (chi square) was used to assess association between the knowledge with the selected variables. A P-value of less than 0.05 was chosen for statistical significance. Awareness score was analyzed according to the points on the individual sections and was categorized as "high", "moderate" and "low" level. The data obtained was presented in the frequency distribution tables.

\subsection{Ethical Consideration}

The study was conducted only after the approval letter received from research committee of Maharajgunj Nursing Campus. Formal permission was taken from the authority of Tribhuvan University Teaching Hospital (TUTH) and Nursing Supervisor of Maternity ward and Birthing Centre from where data was collected. A structured self-administered questionnaire was used. Besides the approval, self-introduction was given and explained the purpose and objectives of the study to all respondents. Verbal informed as well as written consent was taken from each of the respondents before asking questions. Confidentiality of all respondents was maintained. The content validity of the instrument was established by consulting with research advisor, subject experts and research experts, statistician, the opinion of language expert for their valuable comments and suggestion.

\section{Result and Discussion}

\subsection{Socio-Demographic Characteristics of the Respondents}

Table 1 shows the information of age, religion and ethnicity. The mean age of respondents was 30.46. Among the 103 respondents, Majority $39.2 \%$ of the respondents were of age group 30 - 34 years while 20 - 24 years were few 11.8\%. More than two-fifth (53.4\%) of the respondents were Brahmin/chetri, more than one-fifth were Janajati (36.9\%) while 10\% were others (Madhesi, Dalit). Maximum $89.3 \%$ followed Hinduism while Others (Buddhism, Christianity and Islam) were in small proportion (10.6\%).

Among 103 respondents, $1.94 \%$ of respondents could not read and write and 98.06\% could read and write. Among the respondents who could read and write, above two-fifth (44.6\%) of the respondents had Bachelors and above. Likewise, in terms of occupation, $35.0 \%$ were in service and $33.4 \%$ were in business. Only $4 \%$ were in agriculture. In terms of residency, $72.8 \%$ of respondents were from 
Table 1. Socio-demographic characteristics of respondents.

\begin{tabular}{|c|c|c|}
\hline Characteristics & Number & Percentage \\
\hline \multicolumn{3}{|l|}{ Age (in years) } \\
\hline $20-24$ & 12 & 11.8 \\
\hline $25-29$ & 27 & 26.5 \\
\hline $30-34$ & 40 & 39.2 \\
\hline$\geq 35$ & 23 & 22.5 \\
\hline \multicolumn{3}{|l|}{ Mean $\pm \mathrm{SD}=30.46+5.01$} \\
\hline \multicolumn{3}{|l|}{ Religion } \\
\hline Hinduism & 92 & 89.3 \\
\hline Others (Buddhism, Christianity, Islam) & 11 & 10.6 \\
\hline \multicolumn{3}{|l|}{ Ethnicity } \\
\hline Bhrahmin/chetri & 55 & 53.4 \\
\hline Janajati & 38 & 36.9 \\
\hline Others (Madhesi, Dalit) & 10 & 9.7 \\
\hline \multicolumn{3}{|l|}{ Educational status } \\
\hline Cannot read and write & 2 & 1.94 \\
\hline \multicolumn{3}{|l|}{ Can read and write $(\mathrm{n}=101)$} \\
\hline Primary level $(1-5)$ & 10 & 9.9 \\
\hline Secondary level $(6-10)$ & 23 & 22.8 \\
\hline Higher secondary level $(10+2)$ & 23 & 22.8 \\
\hline Bachelors and above & 45 & 44.6 \\
\hline \multicolumn{3}{|l|}{ Occupation } \\
\hline Service & 36 & 35.0 \\
\hline Business & 34 & 33.4 \\
\hline Labor & 29 & 27.7 \\
\hline Agriculture & 4 & 3.9 \\
\hline \multicolumn{3}{|l|}{ Residence } \\
\hline Urban & 28 & 27.2 \\
\hline Rural & 75 & 72.8 \\
\hline \multicolumn{3}{|l|}{ Type of family } \\
\hline Nuclear & 40 & 38.8 \\
\hline Joint & 63 & 61.2 \\
\hline
\end{tabular}

rural area while $27.2 \%$ were from urban area. Concerning type of family, $61.2 \%$ of respondents were from joint family whereas $38.8 \%$ of respondents were from nuclear family. Concerning sex of recent child, $60.2 \%$ were male while $39.8 \%$ were female.

Out of 103 respondents, $52.42 \%$ respondents claimed radio/television, $48.54 \%$ 


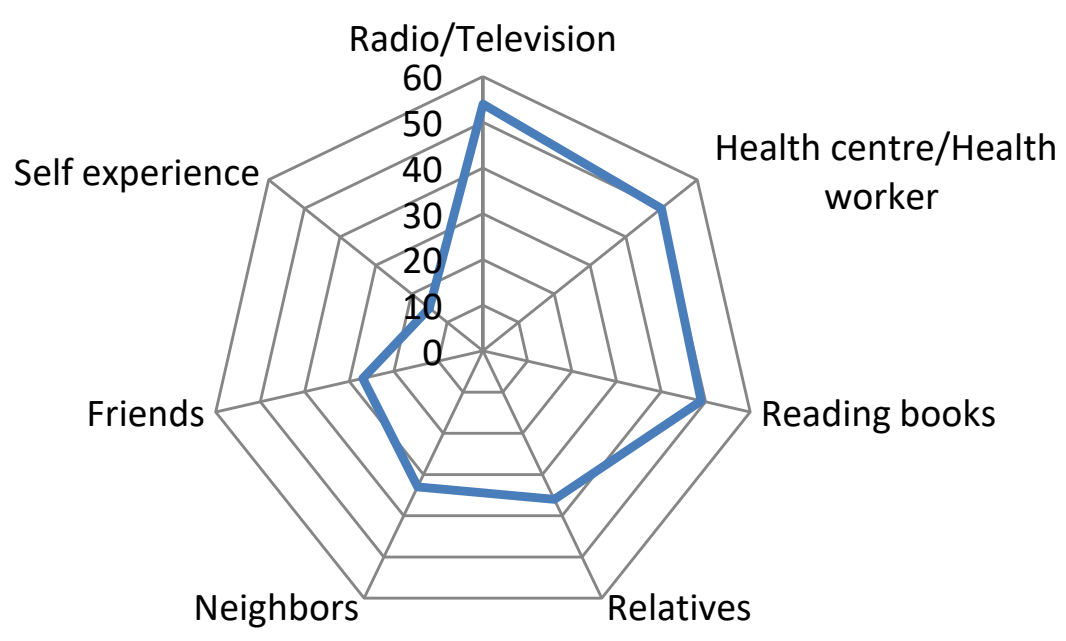

Figure 1. Sources of information.

health centre/health worker, $47.57 \%$ reading books, $34.95 \%$ relatives, $32.03 \%$ neighbors, $32.03 \%$ friends and $14.5 \%$ self-experience as their source of information regarding newborn danger signs (Figure 1).

\subsection{Respondents Awareness on Newborn Danger Signs}

In this study Newborn refers to Infant within 7 days of life, and Newborn danger signs refers to not feeding well, convulsions, lethargy, fever (hot to touch), hyperthermia, hypothermia (cold to touch), jaundice, umbilical redness or pus draining, skin boils, fast breathing, grunting, severe chest indrawing, eye infection, bulging fontanels and vomiting; Father refers to all those men whose wives have delivered the newborn baby and available at the time of data collection.

Awareness on Newborn and Newborn Danger Signs: Out of 103 respondents, more than three-fifth $(60.2 \%)$ of respondents answered newborn is a baby since birth to 7 days of life where nearly two-fifth answered baby since birth to 28 days of life. Here, $90 \%$ of respondents answered signs that indicate severe illness among newborn as a meaning of newborn danger signs.

Awareness on Newborn and Newborn Danger Signs: Gastrointestinal Features and Respiratory Features: $70.9 \%$ were aware about unable to feed as newborn danger sign where $68.49 \%$ respondent answered not sucking milk as before and $42.46 \%$ respondents answered not passing urine adequately as features that indicate unable to feed. Likewise, $80.6 \%$ were aware of vomiting every time after feed as newborn danger sign. Similarly, among 103 respondents, $81.6 \%$ inward movement of chest, $83.5 \%$ of respondents were aware of fast breathing and $49.5 \%$ nasal flaring. The present study is similar to Gurung [37] which found features unable to feed $76 \%$.

Awareness of Respondents on Newborn Danger Signs. Neurological Features, Fever and Hypothermia: Among 103 respondents, 77.7\% of respondents were aware of convulsion where $57.5 \%$ answered shivering movement of body, $38.75 \%$ answered stiffness of hands and limbs and $13.75 \%$ answered vacant stare 
of eyes as features of convulsion. Likewise, $66.0 \%$ were aware of Lethargy. Here, $67.64 \%$ answered difficult to wake up baby even after intense effort and 35.29\% answered unable to wake up baby for feeding. Regarding bulging fontanels, $75.7 \%$ were aware. Likewise, out of 103 respondents, $78.6 \%$ were aware of fever as newborn danger sign where $58.02 \%$ of respondents answered forehead is hot to touch and $51.85 \%$ respondents answered mother complains for hot sensation in mother's nipple when baby is breast feeding. Similarly, $90.3 \%$ of respondents were aware of hypothermia. Here, $62.36 \%$ response remains cold even after keeping in chest and $40.86 \%$ response trunk and hands are cold to touch as features that indicate hypothermia. The findings of this study, that is $78.6 \%$ were aware of fever and $90.3 \%$ of respondents were aware of hypothermia, are close to Shakya [38] that 50\% respondents had stated the danger signs (fever) and distant to the statistical findings of Gurung [37] which stated " $8 \%$ respondents were aware of hot and cold to touch".

Awareness of Respondents on Newborn Danger signs. Jaundice and Local Signs of Infection: Among 103 respondents, 93.2\% respondents were aware of jaundice. $72.91 \%$ of respondents answered yellowish discoloration of eyes as the first sign that indicate jaundice. Regarding eye infection, $89.3 \%$ were aware of it. This study shows $75.7 \%$ of respondents were aware of umbilical infection and $81.6 \%$ were aware of skin pustules. Similarly, $93.2 \%$ respondents were aware of jaundice which contrasts to Shakya [38] which was $13 \%$. In addition, $83.5 \%$ of respondents were aware of fast breathing, 83.5\% inward movement of chest and 49.5\% nasal flaring. This is not supported by the findings of both Shakya [38] that stated " $50 \%$ respondents had stated the danger signs (Pneumonia, Fever)" and Gurung [37] that stated "14\% of them said coughing and breathing difficulty". Accordingly, 89.3\% respondents were aware of pus drainage from eye and $75.7 \%$ respondents were aware of bulging fontanel. $80.6 \%$ were aware of vomiting every time after feed as newborn danger signs. According to Gurung [37] it was just $2 \%$.

\subsection{Level of Awareness of Respondents Regarding Newborn Danger Signs}

Awareness regarding newborn danger signs refers to the correct response obtained from fathers to the awareness questions on Danger Signs of Newborn as measured by structured interview schedule; Awareness Score refers to each of the correct response of awareness related question carried 1 mark. The score obtained by the respondent was divided by total mark i.e. 31 and multiplied by 100 to calculate percentage and awareness was categorized into 3 levels i.e. Low level $(<50 \%)$, Moderate level $(50 \%-75 \%)$ and High level $(>75 \%)$ which is adopted from Al-battawi [39] (Figure 2).

Out of 103 respondents $63.1 \%$ of respondents had moderate level of awareness whereas $28.2 \%$ of respondents had low level of awareness and $8.7 \%$ of respondents had high level of awareness regarding newborn danger signs. Shakya 


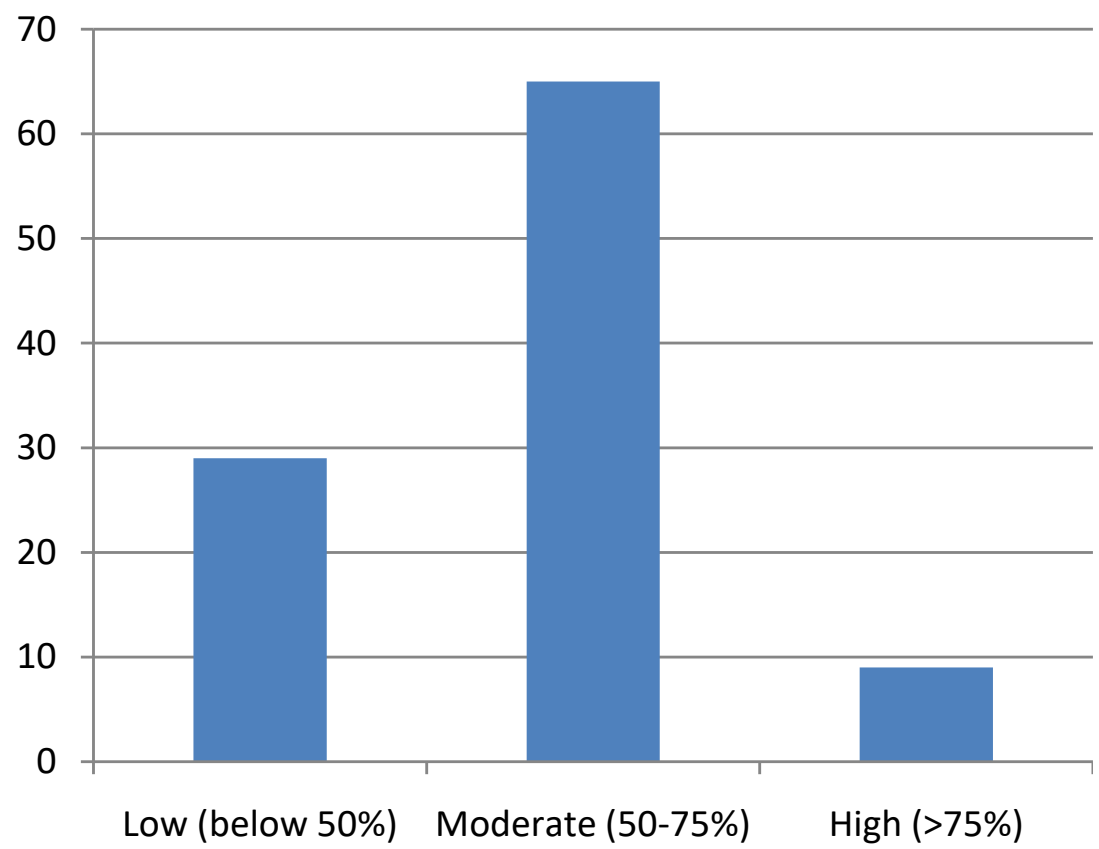

Figure 2. Fathers' level of awareness.

(2016) stated the similar finding that $57 \%$ had knowledge of common problem (Poor sucking, eye infection and cord infection).

\subsection{Respondents Health Seeking Behavior and Awareness on Precautions to Prevent Danger Signs}

Regarding health seeking behavior of respondents, almost all i.e. $98 \%$ of the respondents told that they should take their newborn to the health center in case of illness [37] which comprises similar finding of this study i.e. $96.1 \%$ preferred health facility (Table 2).

\subsection{Association between Level of Awareness and Socio-Demographic Characteristics of Respondents}

The dependent variable of the study is level of awareness of fathers regarding newborn danger signs. The independent variables of this study framed under two broad categories, Socio-demographic Variables and sources of information. In socio-demographic variable, variables like age, ethnicity, religion, education, occupation and residence were taken. While, for the source of information, variables are mass media, family members /relatives, friends and health center/health professionals (Table 3).

This study depicts that there is no statistical significant association between the level of awareness among fathers regarding newborn danger signs with age, religion, ethnicity, educational status, occupation and residency of fathers. Very few literatures were found to support the study. This resulted into discrepancies among the findings of the study and the relevant findings published in the previous literatures. Hence, validated comparisons could not be made. 
Table 2. Respondents health seeking behavior and awareness on precautions to prevent danger signs.

\begin{tabular}{ccc}
\hline Variables & Number & Percentage \\
\hline Seek for treatment (first priority) & & \\
Visit health facility & 99 & 96.1 \\
Precautions to prevent danger signs ${ }^{\star}$ & & \\
Cleanliness & 95 & 92.23 \\
Immunization & 86 & 83.49 \\
Exclusive breastfeeding & 80 & 77.66 \\
Keep the baby warm & 75 & 72.81 \\
\hline
\end{tabular}

Multiple response*

Table 3. Association between level of awareness and socio-emographic characteristics of respondents.

\begin{tabular}{|c|c|c|c|c|c|}
\hline \multirow{2}{*}{ Variables } & \multicolumn{4}{|c|}{ Level of Awareness on Newborn Chi - square } & \multirow{2}{*}{$\begin{array}{c}\text { P-Value } \\
x 2\end{array}$} \\
\hline & & Danger Sign & & Value $(\sigma)$ & \\
\hline Age of father & Low & Moderate & High & & \\
\hline Less than 30 & 13 & 24 & 3 & 0.653 & 0.721 \\
\hline 30 and above & 16 & 41 & 6 & & \\
\hline \multicolumn{6}{|l|}{ Religion } \\
\hline Hinduism & 25 & 59 & 8 & 0.826 & 0.662 \\
\hline Others (Buddhism, Christianity and Islam) & 4 & 5 & 1 & & \\
\hline \multicolumn{6}{|l|}{ Ethnicity } \\
\hline Brahmin/Chhetri & 12 & 36 & 7 & 3.936 & 0.140 \\
\hline Janjati and others (Dalit, Madhesi) & 17 & 29 & 2 & & \\
\hline \multicolumn{6}{|l|}{ Occupation of Father } \\
\hline Service & 11 & 20 & 5 & 3.151 & 0.533 \\
\hline Business & 9 & 24 & 1 & & \\
\hline Labor and Agriculture & 9 & 21 & 3 & & \\
\hline \multicolumn{6}{|l|}{ Area of Residence } \\
\hline Urban & 8 & 18 & 2 & 0.123 & 0.940 \\
\hline Rural & 21 & 47 & 7 & & \\
\hline
\end{tabular}

\section{Conclusion}

Study findings show that most of the respondents had moderate level of awareness and minority of the respondents had high level of awareness on newborn danger signs. There was no statistically significant association between level of awareness and age, religion, ethnicity, education, occupation, residence and type of family. This study in general concludes that fathers in general have moderate level of awareness regarding newborn danger signs. This study was conducted on maternity ward and birthing centre of a tertiary level hospital only so, the re- 
sult may not be generalized to other areas of Nepal. Also, as non-probability purposive sampling technique was used for this study, it is vulnerable to biasness. The findings of the study could be used by health care professionals to plan \& implement educational program to maintain paternal awareness regarding newborn danger signs. The study might be helpful to provide additional background and literature to other related studies in future. A well planned discharge teaching at the time of delivery and postnatal visit might upgrade the awareness of fathers regarding newborn danger signs. Similar type of study might be conducted in large scale in community.

\section{Conflicts of Interest}

The authors declare no conflicts of interest regarding the publication of this paper.

\section{References}

[1] Kayode, G., Grobbee, D., Amoakoh-Coleman, M., Ansah, E., Uthman, O. and Klipstein-Grobusch, K. (2017) Variation in Neonatal Mortality and Its Relation to Country Characteristics in Sub-Saharan Africa. BMJ Global Health, 2, A49-A49. https://doi.org/10.1136/bmigh-2016-000260.130

[2] World Health Organization (2019) Newborns: Reducing Mortality. WHO Fact Sheets.

https://www.who.int/news-room/fact-sheets/detail/newborns-reducing-mortality

[3] UNICEF (2018) Neonatal Mortality. UNICEF Data: Monitoring the Situation of Children and Women.

[4] Sankar, M.J., Natarajan, C.K., Das, R.R., Agarwal, R., Chandrasekaran, A. and Paul, V.K. (2016) When Do Newborns Die? A Systematic Review of Timing of Overall and Cause-Specific Neonatal Deaths in Developing Countries. Journal of Perinatology, 36, S1-S1. https://doi.org/10.1038/jp.2016.27

[5] Paudel, D. (2013) Trends and Determinants of Neonatal Mortality in Nepal: Further Analysis of the Nepal Demographic and Health Survey, 2001-2011. Ministry of Health and Population.

[6] Oza, S., Cousens, S.N. and Lawn, J.E. (2014) Estimation of Daily Risk of Neonatal Death, Including the Day of Birth, in 186 Countries in 2013: A Vital-Registration and Modelling-Based Study. The Lancet Global Health, 2, e635-e644. https://doi.org/10.1016/S2214-109X(14)70309-2

[7] Greene-Cramer, B., Boyd, A.T., Russell, S., Hulland, E., Tromble, E., Widiati, Y. and Handzel, E. (2019) Systematic Identification of Facility-Based Stillbirths and Neonatal Deaths through the Piloted Use of an Adapted RAPID Tool in Liberia and Nepal. PLoS ONE, 14, e0222583. https://doi.org/10.1371/journal.pone.0222583

[8] Ekwochi, U., Ndu, I.K., Osuorah, C.D., Amadi, O.F., Okeke, I.B., Obuoha, E. and Obumneme-Anyim, N.I. (2015) Knowledge of Danger Signs in Newborns and Health Seeking Practices of Mothers and Care Givers in Enugu State, South-East Nigeria. Italian Journal of Pediatrics, 41, 18. https://doi.org/10.1186/s13052-015-0127-5

[9] Chowdhury, S.K., Billah, S.M., El Arifeen, S. and Hoque, D.M.E. (2018) Care-Seeking Practices for Sick Neonates: Findings from Cross-Sectional Survey in 14 Rural Sub-Districts of Bangladesh. PLOS ONE, 13, e0204902. 
https://doi.org/10.1371/journal.pone.0204902

[10] Shamba, D., Tancred, T., Hanson, C., Wachira, J. and Manzi, F. (2019) Delayed Illness Recognition and Multiple Referrals: A Qualitative Study Exploring Care-Seeking Trajectories Contributing to Maternal and Newborn Illnesses and Death in Southern Tanzania. BMC Health Services Research, 19, 225. https://doi.org/10.1186/s12913-019-4019-z

[11] Agarwal, S., Srivastava, K. and Sethi, V. (2007) Maternal and Newborn Care Practices among the Urban Poor in Indore, India: Gaps, Reasons and Possible Program Options. Urban Health Resource Centre, New Delhi.

https://doi.org/10.2139/ssrn.2810871

[12] Khan, M.H., Das, S., Khalique, N. and Goel, P. (2014) Knowledge of Pregnant Women about Danger Signs in Newborns Requiring Medical Consultation in Periurban Area of Aligarh. Indian Journal of Scientific Research, 5, 41.

https://doi.org/10.5958/j.0976-5506.5.2.098

[13] Young Infants Clinical Signs Study Group (2008) Clinical Signs That Predict Severe Illness in Children under Age 2 Months: A Multicentre Study. The Lancet, 371, 135-142. https://doi.org/10.1016/S0140-6736(08)60106-3

[14] Smitherman, H.F. and Macias, C.G. (2016) Febrile Infant (Younger than 90 Days of Age): Outpatient Evaluation-UpToDate.

[15] Sweet, L.R., Keech, C., Klein, N.P., Marshall, H.S., Tagbo, B.N., Quine, D. and Muñoz, F.M. (2017) Respiratory Distress in the Neonate: Case Definition \& Guidelines for Data Collection, Analysis, and Presentation of Maternal Immunization Safety Data. Vaccine, 35, 6506. https://doi.org/10.1016/j.vaccine.2017.01.046

[16] World Health Organization (2017) WHO Recommendations on Newborn Health: Guidelines Approved by the WHO Guidelines Review Committee (No. WHO/MCA/17.07). World Health Organization.

[17] Chiabi, A., Djoupomb, M., Mah, E., Nguefack, S., Mbuagbaw, L., Zafack, J. and Tchokoteu, P.F. (2011) The Clinical and Bacteriogical Spectrum of Neonatal Sepsis in a Tertiary Hospital in Yaounde, Cameroon. Iranian Journal of Pediatrics, 21, 441.

[18] Opiyo, N. and English, M. (2011) What Clinical Signs Best Identify Severe Illness in Young Infants Aged 0-59 Days in Developing Countries? A Systematic Review. Archives of Disease in Childhood, 96, 1052-1059.

https://doi.org/10.1136/adc.2010.186049

[19] Abdulsalam, M., Ibrahim, M. and Asani, M.O. (2015) An Overview of Neonatal Conjuctivitis.

https://go.gale.com/ps/anonymous?id=GALE\%7CA432165739\&sid=googleScholar

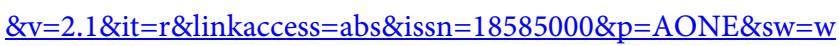

[20] Gul, S.S., Jamal, M. and Khan, N. (2010) Ophthalmianeonatorum. Journal of College of Physicians and Surgeons Pakistan, 9, 595-598.

https://www.ncbi.nlm.nih.gov/pubmed/20810051

[21] Fransen, L., Van den Berghe, P., Mertens, A., Van Brussel, K., Clara, R.R. and Piot, P. (1987) Incidence and Bacterial Etiology of Neonatal Conjunctivitis. Europian Journal Pediatrics, 146, 152-155. https://doi.org/10.1007/BF02343222

[22] Narchi, H. andKulaylat, N. (1999) Feeding Problems with the First Feed in Neonates with Meconium-Stained Amniotic Fluid. Paediatrics \& Child Health, 4, 327-330. https://doi.org/10.1093/pch/4.5.327

[23] Lunze, K., Bloom, D.E., Jamison, D.T. and Hamer, D.H. (2013) The Global Burden of Neonatal Hypothermia: Systematic Review of a Major Challenge for Newborn 
Survival. BMC Medicine, 11, 24. https://doi.org/10.1186/1741-7015-11-24

[24] Dumbaugh, M., Tawiah-Agyemang, C., Manu, A., ten Asbroek, G.H., Kirkwood, B. and Hill, Z. (2014) Perceptions of, Attitudes towards and Barriers to Male Involvement in Newborn Care in Rural Ghana, West Africa: A Qualitative Analysis. BMC Pregnancy and Childbirth, 14, 269. https://doi.org/10.1186/1471-2393-14-269

[25] Herland, M.D., Hauge, M.I. and Helgeland, I.M. (2015) Balancing Fatherhood: Experiences of Fatherhood among Men with a Difficult Past. Qualitative Social Work, 14, 242-258. https://doi.org/10.1177/1473325014528737

[26] Ministry of Health (2016) Nepal Demographic Health Survey 2016.

[27] Nepal Demoghraphic and Health Surveys (2013) Further Analysis of the Nepal Demographic and Health Surveys, 2001-2011. Trends and Determinants of Neonatal Mortality in Nepal, 1-42.

[28] World Health Organization (2013) Pocket Book of Hospital Care for Children: Guidelines for the Management of Common Childhood Illnesses. World Health Organization.

[29] Moxon, S.G., Lawn, J.E., Dickson, K.E., Simen-Kapeu, A., Gupta, G., Deorari, A. and Kumar, R. (2015) Inpatient Care of Small and Sick Newborns: A Multi-Country Analysis of Health System Bottlenecks and Potential Solutions. BMC Pregnancy and Childbirth, 15, S7. https://doi.org/10.1186/1471-2393-15-S2-S7

[30] UN IGME, The United Nations Inter-Agency Group for Child Mortality Estimation. (2015) Levels \& Trends in Child Mortality, Report 2015. UNICEF, United Nations Children's Fund. WHO, World Health Organization.

[31] Yogman, M., Garfield, C.F. and Committee on Psychosocial Aspects of Child and Family Health (2016) Fathers' Roles in the Care and Development of Their Children: The Role of Pediatricians. Pediatrics, 138, e2016112. https://doi.org/10.1542/peds.2016-1128

[32] American Psychological Association (2013) The Changing Role of the Modern Day Father. https://www.apa.org/pi/families/resources/changing-father

[33] Kvols, K. (2015) http://peaceinyourhome.com/role-of-the-father-in-newborns-life

[34] Bhatta, D.N. (2013) Involvement of Males in Antenatal Care, Birth Preparedness, Exclusive Breast Feeding and Immunization. BMC Pregnancy and Childbirth, 13, 14. http://www.biomedcentral.com/1471-2393/13/14 https://doi.org/10.1186/1471-2393-13-14

[35] Gyanwali, S. and Lamsal, A. (2016) Knowledge Regarding Care of First Newborn Baby among Fathers Attending a Tertiary Level Maternity Hospital of Nepal. Journal of Family Medicine \& Community Health, 3, 1-5.

[36] Aryal, B. and Koirala, R. (2019) Frequency of Risk Factors for Coronary Artery Disease among Cardiac Patients at Manmohan Cardiothoracic Vascular and Transplant Center, Nepal: Cross-Sectional Study. Journal of Asian Scientific Research, 9, 20-28. https://doi.org/10.18488/journal.2.2019.93.20.28

[37] Gurung, A. (2003) Paternal Knowledge and Attitude. NHRC. http://library.nhrc.gov.np:8080/nhrc/handle/123456789/365

[38] Shakya, M.J. (2016) Determinants of Newborn Care at Home among the Parents Attending Maternal. Journal of Chitwan Medical College, 6, 34-39. https://doi.org/10.3126/jcmc.v6i1.16653

[39] Al-Battawi, J.I. (2008) Development of an Educational Booklet for Women about Self Care During Pregnancy. Journal of High Institute of Public Health, 38, 27-53. https://doi.org/10.21608/jhiph.2008.20866 